\title{
O Conselho Nacional de Educação e as POLÍTICAS DE PRIVATIZAÇÃO DA EDUCAÇÃO SUPERIOR NO GOVERNO DE FHC*
}

\author{
Andréia Ferreira da Silva**
}

RESUMO

O presente estudo analisa a criação e atuação do Conselho Nacional de Educação (CNE) no processo de implementação das políticas de ampliação e diversificação das instituições de ensino superior, via iniciativa privada, implementadas no governo do presidente Fernando Henrique Cardoso. O CNE é compreendido como um lócus onde se confrontam diferentes projetos para a educação no Brasil e, especificamente, para a educação superior. Para alcançar esse objetivo, a presente investigação analisa as principais reformas na organização e nas funções do CNE e a trajetória de seus membros como uma possibilidade de se conhecer a que projetos de educação e de ensino superior se vinculam.

Palavras-chave: neoliberalismo; privatização da educação superior; Conselho Nacional de Educação.

A partir de 1970, no contexto da crise de acumulação do capital, da crise do Estado de bem-estar social e da implantação dos processos de reestruturação produtiva, ${ }^{1}$ vem ocorrendo a internacionalização crescente das relações capitalistas de produção marcada, de um lado, pela concentração e centralização do capital em escala mundial e, de outro, pela dispersão geográfica da produção e do consumo. Nessa conjuntura, a doutrina neoliberal passa a ser apresentada como a única alternativa para a crise, conquistando a hegemonia nas sociedades

\footnotetext{
* Artigo recebido em 5/4/2005 e aprovado em 25/5/2005.

** Doutora em Educação pela Universidade Federal Fluminense e professora da Faculdade de Educação da Universidade Federal de Goiás. E-mail: silvaandreia@uol.com.br
} 
contemporâneas. A nova doutrina hegemônica tem como fundamentos: a) a desregulamentação da economia; b) a flexibilização das relações capital-trabalho; c) a privatização; e d) a redução dos gastos e do déficit público.

Com a crise do welfare state, o pensamento neoliberal tornou-se referência para a redefinição das funções do Estado, com reformas estruturais, políticas e econômicas, que questionam tanto a intervenção estatal na economia quanto o padrão de proteção social alcançado, sobretudo, nos chamados países centrais. Assim, enquanto a constituição do welfare state possibilitou uma certa "desmercadorização" dos serviços públicos, principalmente de educação, saúde, previdência social e assistência social, o neoliberalismo vem se pautando por sua "remercadorização" (FALEIROS, 2000).

As políticas sociais e econômicas neoliberais objetivam reduzir o âmbito de ação das instituições públicas e ampliar os campos de investimento privado em áreas rentáveis, sob o argumento de liberar o Estado para o cumprimento de suas funções sociais. Dessa forma, implanta-se um processo de "privatização seletiva" (LAURELL, 2000), no qual as áreas sociais rentáveis e promissoras são entregues à "burguesia de serviços" que, por sua vez, recebe inúmeros benefícios do governo para implantar e expandir "seus negócios". Boito Jr. (1999) utiliza o termo "burguesia de serviços" para caracterizar a fração da burguesia ligada, principalmente, à exploração dos serviços de saúde, educação e previdência privada, nicho crescente dos serviços públicos que vêm sendo transformados em mercadoria.

A redefinição do modelo de políticas sociais vem significando, de acordo com Coutinho (2001), a passagem do modelo europeu, pautado nas lutas por direitos universais a partir do princípio da igualdade, para o modelo americano, que propõe a focalização dos direitos sociais, o princípio da equiidade e a fragmentação das lutas, mediante o fortalecimento da organização de grupos sociais em torno de interesses pontuais. Nesse sentido, vive-se hoje a "americanização" das políticas sociais, ou seja, a instituição de serviços públicos restritos, mínimos e reduzidos à população de baixa renda. No Brasil, na área educacional, essa orientação manifesta-se na focalização dos gastos federais com o ensino fundamental e a redução, cada vez mais acentuada, de investimentos no ensino superior, que se torna campo aberto aos investimentos privados. 
A flexibilização do padrão de educação superior ganha força a partir da construção de um consenso de que os serviços públicos, em geral, não são eficientes nem eficazes. No caso específico da educação, a universidade pública passa a ser vista como incapaz de desempenhar sozinha sua função formadora, fazendo da iniciativa privada uma instância necessária à prestação desse serviço à população. Diante da ampliação das exigências da qualificação do trabalhador, dinamizadas, entre outras, pelas mudanças nos processos de produção, o ensino superior passa a ser exigido por camadas mais amplas da sociedade, a iniciativa privada passa a ser percebida como "parceira" indispensável do Estado na oferta da educação superior

Os anos de 1990, balizados pela conversão da privatização da educação superior em política pública, foram marcados pela expansão acelerada das matrículas no ensino superior privado. No ano de 1999, foram criados 745 novos cursos superiores, para uma média dos anos anteriores inferior a 200 cursos por ano. No período entre 1996 e 2000 foram abertos 2.016 novos cursos em todo o país.

Nesse processo de ampliação e diversificação das instituições de ensino superior no país, durante os anos de 1990, o conselho responsável por debater e normatizar a educação no país foi alvo de inúmeras críticas e denúncias por causa de seu caráter clientelista: a ligação de alguns de seus membros com setores privados do ensino, principalmente no que tange ao ensino superior. Inicialmente, o Conselho Federal de Educação (CFE) e, posteriormente, o Conselho Nacional de Educação (CNE) ocuparam as manchetes de jornais com tais acusações. O CFE foi extinto em 1994 como forma de livrar a educação de tantas denúncias e foi criado o CNE, que deveria pautar-se pela ética e transparência nos debates e nas deliberações acerca da educação nacional. Entretanto, a extinção do CFE não foi suficiente para impedir que novas denúncias de clientelismo e favorecimento de determinados segmentos do ensino privado voltassem a ocorrer no novo conselho.

A partir desse debate acerca do caráter do CNE e de sua atuação em relação ao ensino superior brasileiro, o presente texto busca analisar a composição do Conselho Nacional de Educação, especificamente da Câmara de Educação Superior (CES-CNE), no processo de definição e implementação das políticas de diversificação e privatização das instituições de ensino superior no período em estudo. Assim, este estudo pretende revelar as relações de força existentes no interior do CNE que 
expressam e fazem parte das relações de força existentes no Estado, em sentido ampliado. Para alcançar esse objetivo, a presente investigação analisa as principais reformas na organização e nas funções do CNE e a trajetória de seus membros, como uma possibilidade de conhecer-se a que projetos de educação e ensino superior se vinculam.

Neste trabalho, o Conselho Nacional de Educação é entendido como um "terreno em que se defrontam algumas das principais facções interessadas em afirmar sua autoridade de legislar em matéria de política educacional, uma arena de luta entre interesses favoráveis e contrários" (MicELI, 2001, p. 309) às políticas educacionais implementadas no governo de FHC. Apesar da existência de divergências, é possível afirmar a realização de alianças, provisórias ou não, que buscaram fortalecer determinadas concepções no interior do conselho.

No período em estudo, é possível perceber basicamente a existência de três grupos ${ }^{2}$ que disputaram a prevalência de suas concepções no CNE: a) setores que reivindicam a implementação de políticas que garantam o fortalecimento das instituições de ensino superior públicas e um maior controle estatal das instituições privadas de ensino superior; b) as facções que defendem a "burguesia de serviços educacionais"3 e defendem a ampliação da participação do segmento privado na oferta do ensino superior e a limitação do controle estatal nessa "iniciativa empresarial"; e c) os segmentos que compartilham/defendem a ampliação da oferta do ensino superior via, majoritariamente, a privatização, a partir da criação de um sistema nacional de avaliação da qualidade proposta pelo governo FHC.

De acordo com Weber (2002, p. 93), a questão da "formulação de um conceito de qualidade da formação em nível superior e o estabelecimento de indicadores compatíveis com essa concepção foram grandes objetos de disputa e de confronto" entre os membros da Câmara da Educação Superior no período analisado neste texto. Contudo, a existência de diferentes interesses, diferentes conceitos de educação superior e sua qualidade fez com que essa discussão se constituísse, para alguns conselheiros, na defesa intransigente de interesses econômicos particulares no interior da CSE-CNE.

Objetivando compreender as relações de força existentes no interior do CNE, a presente investigação historia, brevemente, outras experiências de conselhos de educação existentes no Brasil; analisa as diferentes propostas de CNE presentes nas discussões em torno da aprovação da 
Lei n. 9.394/1996; apresenta as medidas provisórias que extinguiram o Conselho Federal de Educação em outubro de 1994 (MP n. 661/1994) e criaram o CNE (Lei n. 9.131/1995); estuda as principais reformas implantadas na composição e nas funções do conselho, especificamente, em relação ao ensino superior; e examina a trajetória dos membros da CES-CNE.

Conselho Nacional de EduCAÇão - Um BREVE históRICO

Desde o início do período republicano, o governo brasileiro contou com a existência de conselhos de educação, organizados com o intuito de discutir e/ou definir as políticas para a educação. O primeiro, o Conselho Superior de Instrução, foi criado pela Reforma Benjamim Constant, ${ }^{4}$ em 1891. A Revolução de 30, pela Reforma Francisco Campos (Decreto n. 19.850, de abril de 1931), também organizou um Conselho Nacional de Educação ${ }^{5}$ com funções consultivas.

Esse conselho, como "órgão consultivo do ministro da Educação e Saúde Pública nos assuntos relativos ao ensino", tinha um caráter estrito de assessoria ao trabalho realizado pelo ministério. Para Miceli (2001), ${ }^{6}$ naquele período, "Os conselhos não são senão arenas abertas à negociação de interesses, num momento de transição entre as formas de dominação oligárquica vigentes na República Velha e a consolidação de uma dominação burocrática de perfil autoritário" (p. 296). Em decorrência desse quadro, a composição do CNE, marcada pela existência de diferentes grupos de interesses, expressava as disputas existentes na sociedade brasileira de então.

A Constituição de 1934 mantém a definição de um Conselho Nacional de Educação e refere-se aos conselhos estaduais. Em 1936, o CNE passa por uma reestruturação que significa a ampliação do espaço ocupado pelos representantes dos "educadores profissionais" que se constituíam, naquele momento, como campo de especialistas da educação. ${ }^{8}$

A Lei n. 4.024, de 20 de dezembro de 1961, cria o Conselho Federal de Educação. Esse conselho, marcado em seu nascedouro pela vitória das concepções privatistas na primeira Lei de Diretrizes e Bases da Educação da sociedade brasileira, expressa, em sua composição, a preocupação com a representação das diversas regiões do país, dos diversos graus do ensino e adequada representação do "magistério oficial 
e particular". Romanelli (1978, p. 182) chama a atenção para as atribuições do conselho que, para ela, "deixava de ser um órgão de assessoramento, para ser um superministério".

Lourenço Filho (1967), ao estudar as funções do Conselho Federal de Educação, apresenta uma análise diferente da proposta por Romanelli (1978). Para ele, a Lei n. 4.024/61 não apresenta uma explícita definição dos limites funcionais entre os órgãos que institui. Um exemplo dessa situação consiste, para Lourenço Filho, nos órgãos colegiados, sob a forma dos conselhos de educação, o federal e os estaduais. Para ele:

Torna-se difícil dizer de pronto se o Conselho Federal é parte integrante do Ministério da Educação e da Cultura, ou órgão que a ele se sobrepõe, como difícil é apreender a posição exata dos conselhos estaduais, nos sistemas de ensino dos Estados. Esta dificuldade advém do sistema de delegação de poderes, explícito, que a lei estabelece, sem que discrimine, porém, com perfeita nitidez, as esferas de responsabilidade e os níveis de competência. (1967, p. 244)

As principais funções do Conselho Federal de Educação (CFE) em relação ao ensino superior consistiam na autorização, no reconhecimento e na fiscalização do funcionamento das escolas federais e das escolas mantidas por entidades privadas; no caso de instituições estaduais, competia somente ao CFE o reconhecimento, com exceção do Estado que já tivesse em funcionamento, há mais de cinco anos, de uma universidade estadual. Para todos os cursos superiores, independente do tipo de instituição, caberia ao CFE fixar a duração mínima dos estudos e os planos gerais de ensino ou currículos. Esse conselho foi extinto em 1994, em decorrência das inúmeras denúncias ao seu caráter clientelista e corrupto.

A Constituição Federal de 1988 não faz referência à existência do Conselho Nacional de Educação ou a órgão similar. Nas discussões para a elaboração da LDB, iniciadas logo após a aprovação da Constituição, ou seja, em dezembro de 1988, a proposta de criação e organização de um Conselho Federal de Educação, instância normativa de nível nacional, se fez presente. O projeto de Otávio Elísio explicita o nível de autonomia econômica, financeira e administrativa do conselho, inclusive, definindo que ele deveria dispor de um orçamento próprio aprovado pelo Congresso Nacional. 
O substitutivo Jorge Hage, de 1990, ao tratar do Sistema Nacional de Educação, define que este tem como órgão normativo o Conselho Nacional de Educação e como órgão executivo o Ministério da Educação (art. 10). Prevê também a existência do Fórum Nacional de Educação como uma instância de consulta e de articulação com a sociedade (§ único do art. 10). As atribuições definidas conferem ao CNE papel decisivo na formulação e coordenação da política educacional nacional, na definição do Plano Nacional de Educação e no estabelecimento de diretrizes para os cursos de graduação e pós-graduação, entre outros. Em relação à composição do $\mathrm{CNE}$, pode-se destacar que o presidente da República somente poderá indicar, à sua livre escolha, quatro conselheiros.

O substitutivo manteve a criação do Fórum Nacional de Educação como instância consultiva ${ }^{9}$ do CNE. Esse fórum seria composto, majoritariamente, por representantes indicados pelos vários segmentos da sociedade através de entidades de nível nacional, além de representantes dos poderes constituídos. Caberia ao fórum a função de subsidiar a elaboração do Plano Nacional de Educação. Em relação à sua criação, Saviani (1997) afirma que "só faz sentido instituir na LDB o Fórum Nacional de Educação se ele tiver caráter deliberativo" (1997, p. 65), mas afirma que "a previsão e o respaldo legal ao mecanismo de consulta não deixa de ser preferível à sua exclusão" (p. 65).

O projeto do senador Cid Sabóia, de 1993, ao manter a estrutura do projeto aprovado na Câmara, previa a existência de um Conselho Nacional de Educação que teria, como principais funções, subsidiar a formulação de políticas educacionais e acompanhar sua implementação e propor diretrizes e prioridades para o Plano Nacional de Educação, avaliando a sua execução e articulação com as políticas públicas de outras áreas. Nesse substitutivo, o CNE mantém importante tarefa na definição da organização da educação no Brasil.

Nesse projeto, o número de conselheiros foi reduzido de 30, como era no CFE, para 24, sendo $50 \%$ deles indicados pela presidência da República e 50\% indicados por segmentos sociais organizados vinculados à área educacional, que leva em conta a organização social em nível nacional.

Em outubro de 1994, pela Medida Provisória n. 661/94, ocorreu a transformação do Conselho Federal de Educação em Conselho Nacional de Educação. O CFE foi fechado no governo Itamar Franco por suspeita 
de corrupção, tráfico de influências e, principalmente, por privilegiamento de instituições privadas de ensino superior. Essa MP, ao criar o CNE, seguiu as preocupações que pautavam os debates sobre a LDB naquele momento. A essa medida provisória sucederam-se 14 reedições de MPs ${ }^{10}$ sobre o CNE, até a conversão da MP n. 1.159/94 na Lei n. 9.131/1995, que, além de extinguir o CFE e criar o CNE, institui o Exame Nacional de Cursos. Pode-se observar que a criação do CNE em novembro de 1995, no governo FHC, fez-se em pleno processo de elaboração da LDB; entretanto, sua regulamentação deu-se de forma paralela e à margem das discussões que se travavam sobre a LDB.

Neves (1997), ao estudar os projetos de LDB, apresenta a seguinte pergunta: por que a normatização do Conselho Nacional de Educação constituiu-se em necessidade do governo FHC, a despeito das discussões da LDB que tratavam dessa questão? Para ela, o governo FHC necessitava de amplos poderes para realizar uma profunda reforma em todos os níveis e modalidades de ensino, de acordo com o projeto neoliberal de sociedade e de educação. Por um lado, o CFE da LDB/61, à época ainda em vigor, por ter caráter deliberativo e normativo, impedia que o executivo centralizasse a realização da reforma educacional proposta em sua totalidade, com o mínimo de discussões ou concessões. Por outro lado, o projeto de LDB em discussão, o projeto Cid Sabóia, dava poderes efetivos ao CNE, que deveria dividi-lo com o executivo central. Dessa forma, tornou-se mais estratégico alterar a $\mathrm{LDB} / 61 \mathrm{em}$ vigor, retirando do CNE seu poder deliberativo. Para Neves (1997, p. 2): “o CNE foi criado para que o poder executivo pudesse ampliar seu poder de decisão, ao mesmo tempo que mantinha o aspecto formal da democracia neoliberal via a existência de um "conselho democrático"”.

O Conselho Nacional, que nem sequer havia sido mencionado no primeiro projeto elaborado pelo senador Darcy Ribeiro, na versão final, foi indicado apenas uma vez. A pouca referência que o projeto Darcy Ribeiro faz ao CNE pode ser explicada pelo fato de esse projeto ser o projeto do governo federal para a LDB e o governo já ter criado o "seu conselho". Saviani (1997) refere-se ao projeto Darcy Ribeiro como um "projeto azarão", por ter corrido por fora do processo democrático de debates para a aprovação da LDB.

Na LDB, aprovada em dezembro de 1996, a referência ao CNE é feita da seguinte forma: "Na estrutura educacional, haverá um Conselho Nacional de Educação, com funções normativas e de supervisão e de 
atividade permanente, criado por lei" (Art. 9, inciso IX). Entretanto, a lei que regulamentaria as funções e a composição do CNE já estava em vigor desde novembro de 1995.

A aprovação da "Lei Darcy" tornou-se vital para assegurar as mudanças realizadas pelo governo federal no campo educacional. A aprovação do projeto Cid Sabóia, nos termos em que se encontrava até ser superado pelo projeto de Darcy Ribeiro, levaria à revogação da Lei n. 9.131, de 24 de novembro de 1995, o que, certamente, possibilitaria um maior controle das iniciativas do executivo central, podendo-se evitar, ou pelo menos dificultar, a promulgação de decretos presidenciais e o envio, ao legislativo, de projetos de lei e outros dispositivos legais sem discussão prévia. Isto porque:

O CNE, pensado como um órgão revestido das características de autonomia, representatividade e legitimidade, enquanto uma instância permanente e renovada por critérios e periodicidade distintos daqueles que vigoram no âmbito da política partidária, estaria, senão imune, pelo menos não tão vulnerável aos interesses da política miúda. (SAVIANI, 1997, p. 208)

CNE, SUA ORGANIZAÇÃO E COMPOSIÇÃO: QUEM É QUEM?

No início do ano de 1995, antes da promulgação da Lei n. 9.131/ 1995, o recém-empossado ministro da Educação Paulo Renato de Souza afirmava que, de acordo com o programa de governo "Mãos à Obra" para a área da educação, buscava-se "um Conselho menos credenciador e mais avaliador, menos decisório e mais assessor e, finalmente, mais representativo do conjunto da sociedade e não apenas das corporações do segmento da educação" (Folha DE S. PAUlo, 26 mar. 1995). É justamente essa concepção de CNE que estará presente na Lei n. 9.131/ 1995 e norteará as mudanças implementas em sua estrutura, suas funções e sua composição nos anos de 1990 e no início da década seguinte.

Pela lei que regulamenta o CNE, este consiste em um órgão consultivo do Poder Executivo na formulação e avaliação da política educacional. Para o cumprimento dessa função deverá reunir-se ordinariamente a cada dois meses e, extraordinariamente, sempre que convocado pelo ministro. Já suas câmaras, de Educação Básica e Educação 
Superior, se reunirão mensalmente. Seu presidente será eleito por seus pares para um mandato de dois anos, vedada a recondução imediata. Sempre que o ministro comparecer às sessões, presidirá o conselho. $\mathrm{O}$ artigo $2^{\circ}$ da lei informa que as deliberações e os pronunciamentos do Conselho Pleno e das Câmaras do CNE deverão ser homologados pelo Ministério da Educação e do Desporto.

A normatização do conselho define o caráter de assessoramento do CNE e os limites de sua autonomia diante do MEC, visto que todos os seus pronunciamentos e suas decisões deverão ter o aval do ministério. Isso significa que decisões do conselho podem não ser homologadas pelo MEC. Nesse formato, o conselho não tem comunicação direta com a sociedade civil, mas tem como mediador obrigatório o Ministério da Educação, adequando-se, desse modo, à concepção proposta pelo exministro Paulo Renato, "um conselho menos decisório e mais assessor", o que acarreta seu esvaziamento político. Na Lei de Diretrizes e Bases da Educação de 1961 (Lei n. 4.024), o MEC está subordinado às decisões do CFE, enquanto na Lei n. 9.131/1995, o CNE é órgão colaborador do ministério.

A Lei n. 9.131/1995 define os critérios para escolha de conselheiros no que tange à localização espacial (todas as regiões do país) e à abrangência do sistema escolar (níveis e modalidades de ensino). Determina que a escolha dos conselheiros deve recair sobre brasileiro de "reputação ilibada" e que tenha prestado "serviços relevantes" à educação, à ciência e à cultura. Os conselheiros terão mandato de quatro anos, permitida uma recondução para o período imediatamente subseqüente, havendo renovação de metade da câmara a cada dois anos.

O conselho está dividido em Câmara de Educação Básica (CEB) e Câmara de Educação Superior (CES). Os membros são indicados para cada câmara, segundo critérios próprios, e cada uma das câmaras tem atribuições específicas. As câmaras emitirão pareceres e decidirão, privativa e autonomamente, os assuntos a elas pertinentes, cabendo, quando for o caso, recursos ao Conselho Pleno.

O conselho deve ser composto por 24 membros, todos nomeados pelo presidente da República, sendo 50\% diretamente e a outra metade, obrigatoriamente, nomeada mediante consulta a entidades e segmentos da sociedade civil relacionados às áreas de atuação das respectivas câmaras. Essas entidades indicam, para cada câmara, três nomes que subsidiarão a escolha a ser feita pelo presidente da República. Ao se 
constatar que $50 \%$ dos membros do CNE, ou seja, seis conselheiros a cada dois anos, serão indicados pelo presidente, a partir de uma extensa lista de nomes, observa-se um mecanismo que limita a participação democrática da sociedade civil nas questões educacionais. Dessa forma, o conselho tende a se converter em aparelho de governo, e não em aparelho de Estado.

Na definição da composição da Câmara de Educação Superior do CNE deverão ser consultadas "entidades nacionais, públicas e particulares, que congreguem os reitores de universidades, os diretores de instituições isoladas, os docentes, os estudantes e os segmentos representativos da comunidade científica" (Lei n. 9.131/1995, art. 8º , $^{3}$ o). Para garantir um caráter "mais representativo do conjunto da sociedade", foi proposto pelo ministro a inclusão não apenas dos segmentos estritamente da área da educação. A Portaria n. 1.455/1995 define as entidades de trabalhadores e empresários que também deverão ser consultadas para a elaboração da lista tríplice: Central Única dos Trabalhadores (CUT), Confederação Geral dos Trabalhadores (CGT), Confederação Nacional da Agricultura (CNA), Confederação Nacional do Comércio (CNC), Confederação Nacional da Indústria (CNI). A Portaria n. 2.160/1997 acrescenta a essa lista a Confederação Nacional do Transporte (CNT), enquanto a Portaria n. 12/2000 amplia essa relação com a Social Democracia Sindical (SDS).

As entidades do campo educacional que deverão ser consultadas para a elaboração das listas tríplices para a CES, de acordo com a portaria mencionada, são: Academia Brasileira de Ciências (ABC), Academia Brasileira de Educação (ABE), Associação Brasileira de Reitores de Universidades Comunitárias (Abruc), Associação Brasileira de Reitores de Universidades Estaduais e Municipais (Abruem), Associação Nacional de Pós-Graduação e Pesquisa em Educação (Anped), Associação Nacional de Universidades Particulares (Anup), Associação Nacional dos Dirigentes de Instituições Federais de Ensino Superior (Andifes), Conselho de Reitores das Universidades Brasileiras (Crub), Conselho Nacional dos Secretários de Educação (Consed), Força Sindical (FS), Sindicato Nacional dos Docentes das Instituições de Ensino Superior (Andes), Sociedade Brasileira para o Progresso da Ciência (SBPC) e União Nacional dos Estudantes (UNE). Pela Portaria n. 1.883/1999 foram incluídas nessa relação a Associação Nacional de Política e Administração Escolar (Anpae) e a Associação Nacional de Centros Universitários 
(Anaceu). A Portaria n. 31/2002 acrescenta a indicação da Associação de Faculdades e Institutos Superiores (Anafi).

De acordo com a Portaria n. 12/2000, 22 entidades poderiam sugerir nomes para $50 \%$ da composição da CES/CNE. Se, de fato, todas as entidades participassem desse processo, indicando três nomes, o número de indicados seria muito grande, situação que conferiria ao presidente da República um amplo universo de escolha. Além dessa base extensa de escolha, pelo presidente, de representantes da sociedade civil, o executivo central tem suas posições reforçadas no conselho pela participação, como conselheiros natos, dos secretários da Educação Básica e Superior do MEC.

A diversidade das entidades que participam da indicação consiste em outro elemento importante. O que para o ex-ministro Paulo Renato de Souza significaria a possibilidade de "romper os estreitos limites do campo educacional", pode significar, a meu ver, a pulverização das indicações com pouca representatividade no âmbito da sociedade civil. Mais que isso, possibilitar favorecer o alinhamento de entidades de empresários (CNC, CNT, CNI, CNA), sindicatos com um espectro mais conservador (CGT, FS e SNS) e também de associações de empresários educacionais (Anup, Abruc, Anafi, Anaceu). Isso pode ser observado na indicação, feita em 1998 (Portaria n. 3, de 7 de janeiro de 1998), de Carlos Alberto Serpa de Oliveira, ${ }^{11}$ por seis entidades: ABE, Abruem, Anup, CGT, CNC, Crub. Maior consenso houve em relação ao nome de Yugo Okida, ${ }^{12}$ indicado por nove entidades: ABE, Anup, CGT, CNA, CNC, CNI, CNT, CRUB e FS, de um total de 19 previstas na Portaria $n$. 2.160/1997.

Carlos Alberto Serpa de Oliveira e Yugo Okida já eram membros do CNE, com mandato de dois anos, que se encerrava naquele momento. E mais importante ainda é destacar que ambos os conselheiros foram reconduzidos, pelo presidente da República, para a Câmara de Educação Superior a partir de uma lista composta por 16 nomes.

O Decreto s.n., de 10 de março de 1998, também reconduziu, com mandato de quatro anos, Silke Weber, professora da Ufpe, que foi Secretária de Educação do Estado de Pernambuco (indicada em 1995, ao CNE, para a CES-CNE pelo Consed, Anped e SBPC e para a CEBCNE pelo Consed). Foram nomeados, ainda, Arthur Roquete de Macedo, diretor da Fundação Cesgranrio em São Paulo e ex-reitor da Unesp 
(indicado pela CGT e UNE) e Roberto Cláudio Frota Bezerra, reitor da Universidade Federal do Ceará (indicado pela Andifes).

Duas entidades não participaram inicialmente do processo de indicação de nomes para o CNE: a Andes-SN e a UNE. A UNE alterou sua posição e passou a participar desse processo. A Andes-SN vem mantendo a postura de não enviar indicações para composição do CNE, por avaliar que esse conselho possui apenas caráter de homologador das políticas do MEC.

Esse processo de indicação de nomes para o CNE foi marcado por intensa polêmica criada por interpretações diferenciadas da legislação que a regulamentava. Denúncias da falta de transparência, por parte do MEC, na divulgação do número de indicações recebidas por cada nome, levaram o governo a adiar a nomeação dos conselheiros. A partir de então, a CES-CNE ficou com a seguinte composição: Carlos Alberto Serpa de Oliveira, Yugo Okida, Silke Weber, Arthur Roquete de Macedo, Roberto Cláudio Frota Bezerra, Jacques Veloso, Éfrem Maranhão, Eunice Durham, Hésio Cordeiro, José Carlos Almeida, Lauro Zimmer e Abílio Baeta Neves, secretário da Educação Superior do MEC naquele momento.

A Folha de S. Paulo (11/03/1998), ao analisar a composição da CES-CNE, afirmou que, "com esses nomes a câmara ficará com uma maioria de integrantes ligados ao ensino público" (BERNARDES, 11/3/1998), apontando como parte dessa maioria os seguintes conselheiros: Jacques Veloso, ${ }^{13}$ Eunice Durham, ${ }^{14}$ Silke Weber e Hésio Cordeiro ${ }^{15}$ e Éfrem Maranhão. ${ }^{16} \mathrm{Se}$, de fato, as trajetórias profissionais desses nomes estão ligadas ao ensino público não significa que todos eles, principalmente Durham e Maranhão, defendam propostas para o ensino superior diferentes das propostas encaminhadas pelo Ministério da Educação. Pelo contrário, o currículo de alguns desses conselheiros comprova não só a sua simpatia, mas também a sua participação na implementação dos projetos do MEC de privatização da educação superior no país.

Ao contrário da análise divulgada pela Folha de S. Paulo, constatase que a composição da Câmara da Educação Superior do conselho, no início de 1998, foi marcada pela redução da participação dos segmentos comprometidos com um projeto de fortalecimentos da educação superior pública e, inversamente, pela ampliação do setor defensor de um projeto de privatização desse nível de ensino. Dos 12 conselheiros, sete compartilham explicitamente do projeto privatista para o ensino superior. 
É preciso destacar, no entanto, que esse grupo não é homogêneo. Há diferenças significativas entre seus membros no que se refere ao grau de controle a ser exercido pelo poder público na fiscalização das instituições de ensino superior privadas. Devido a essa divergência, os representantes dos empresários do ensino entram em choque com as políticas do governo FHC, quando estas reduzem benefícios financeiros às entidades privadas, redefinem os subsídios às instituições comunitárias e filantrópicas e implementam programas de avaliação, como o Provão, exigência de qualificação docente e verificação das condições de oferta dos cursos. Mas, no que se refere à necessidade da expansão da rede privada, esses dois grupos assumem a mesma postura de combate aos "privilégios" da universidade pública ${ }^{17}$ e da defesa da expansão da rede privada para reduzir o enorme déficit de vagas existente no ensino superior brasileiro.

A leitura da composição do CNE realizada por instituições privadas de ensino também nega a análise da Folha de S. Paulo. É o caso da UniverCidade que, em texto publicado no Jornal do Brasil, afirma que o "Conselho Nacional de Educação, cuja grande maioria de membros não é estatizante, nem discriminadora e está trabalhando modernamente e com firmeza, recuperando o tempo perdido pelas administrações anteriores" (UniverCidade. Jornal do Brasil, 25 fev. 2000).

O Decreto n. 3.295/1999 restringe ainda mais a participação da sociedade civil na definição da composição do CNE ao eliminar a segunda rodada de consultas às entidades indicadoras de nomes. Dessa forma, cabe ao MEC divulgar o nome das entidades que participam do processo, os prazos a serem obedecidos e elaborar lista com as indicações da sociedade civil para ser submetida ao presidente da República.

Em 2000, a composição do CNE foi renovada (Portaria n. 12/ 2000). Para a CES-CNE, o decreto presidencial reconduziu os seguintes conselheiros: Éfrem Maranhão, Eunice Durham, José Carlos Almeida da Silva e Lauro Ribas Zimmer. Maranhão, Almeida da Silva e Zimmer já eram membros do conselho em sua primeira composição em 1996, e Durham assumiu o CNE na vaga criada com a saída de Giannotti, em agosto de 1997. É importante destacar que todos compartilham do projeto de expansão do ensino superior via iniciativa privada. Além destes, foram nomeados Francisco César Sá Barreto ${ }^{18}$ e Vilma de Mendonça Figueiredo. ${ }^{19}$ Os conselheiros que não tiveram seus mandatos renovados foram Jacques Veloso e Hésio Cordeiro, ambos vinculados ao ensino univer- 
sitário público. Com essa nova composição, o perfil da CES-CNE não se alterou, permanecendo a maioria de seus membros defensores das diretrizes de ampliação do ensino superior via o empresariamento. ${ }^{20}$

A mudança mais significativa nas funções da Câmara de Educação Superior do CNE ocorreu com o Decreto n. 3.860, de julho de 2001. As alterações centralizaram, no âmbito do MEC, o processo de autorização, credenciamento e descredenciamento de IES privadas. Com essas mudanças ocorreu uma significativa centralização das decisões no âmbito estrito dos órgãos administrativos do MEC. Pela nova legislação cabe à CES-CNE a definição das normas a serem seguidas pelo Poder Executivo para o credenciamento periódico e o descrendenciamento de IES integrantes do sistema federal de ensino. A sua função recai unicamente na definição de credenciamento e recredenciamento de universidades e centros universitários, bem como de seus respectivos estatutos e suas alterações.

Segundo o decreto, "O credenciamento das faculdades integradas, faculdades, institutos superiores e escolas superiores dar-se-á mediante ato do Poder Executivo (art. 24)". O CNE somente se manifestará em caso de indeferimento de pedido de credenciamento dessas instituições, se houver apresentação de recurso por parte do interessado. Os únicos cursos de graduação que, independentemente do tipo de IES, dependerão da deliberação da CES-CNE para sua criação, credenciamento são os de direito, medicina, odontologia e psicologia.

$\mathrm{O}$ processo de redefinição das funções da CES-CNE, que se iniciou nos anos de 1990, teve prosseguimento com a implantação da MP n. 2.143-34/2001 que atribuiu à câmara "deliberar sobre as normas a serem seguidas pelo Poder Executivo para a suspensão do reconhecimento de cursos e habilitações oferecidos por IES." ${ }^{21}$ Além disso, modificou o parágrafo único do artigo $2^{\mathrm{o}}$ da Lei n. 9.131/1995, indicando que a criação e o reconhecimento de cursos "serão tornados efetivos mediante ato do Poder Executivo, conforme regulamento" (art. 2). Essa transformação, ao definir a necessidade da elaboração de normas específicas para a autorização, credenciamento e recredenciamento de instituições de ensino superior e cursos, deu mais um passo na revisão das funções da Câmara da Educação Superior do CNE em relação ao ensino superior.

O Decreto n. 3.860, de julho de 2001, regulamentando essa lei, detalhava as funções do CNE em relação ao ensino superior. As alterações 
propostas centralizavam, no âmbito do MEC, o processo de autorização, credenciamento e descredenciamento de IES isoladas. Com essas mudanças ocorreu uma significativa diminuição das atribuições da CESCNE, com a conseqüente centralização das decisões no âmbito estrito dos órgãos administrativos do MEC. Ao mesmo tempo, as funções da Sesu e do Inep foram redefinidas.

Para o MEC, essa mudança permitiu à CES-CNE libertar-se do acúmulo de funções para realizar, com primazia, sua função normativa. Nesse sentido, o ex-ministro Paulo Renato afirmou que foi dada ao conselho uma função "mais nobre". Para ele, "O ministério vai agir de acordo com as regras do conselho e este tratará dos casos mais importantes, como a abertura de cursos na área médica e o credenciamento de universidades e centros universitários" (Jornal da Ciência, SBPC, 3 ago. 2001).

Essa alteração implementada pelo governo, sem discussão prévia, em um contexto de inúmeras denúncias ao caráter cartorial do $\mathrm{CNE},{ }^{22}$ principalmente em relação ao ensino superior privado, desencadeou o pedido de exoneração, da Câmara de Educação Superior do CNE, de Eunice Durham. ${ }^{23}$ Ao deixar o Conselho, Durham afirmou, em entrevista à Folha de S. Paulo (23 jul. 2001), que a modificação das funções da CES-CNE "concentra demasiado poder na mão do ministério" e que a redução do poder do conselho contribui para diminuir a transparência dos processos de instituições privadas. ${ }^{24}$ Vale lembrar que, em agosto de 1997, o conselheiro Arthur Giannotti saiu da CES-CNE também questionando a transparência dos processos de credenciamento e recredenciamento de instituições privadas de ensino. ${ }^{25}$

Os dois casos de conselheiros indicados pelo presidente FHC que deixaram o conselho, um direcionando suas críticas ao caráter representativo/corporativo do próprio conselho, enquanto o outro dirigia críticas ao MEC pela ausência de clareza dos objetivos e rumos do ensino superior, expressam as ambigüidades e fragilidades do conselho. Denunciam, mais uma vez, a transformação do CNE, em várias situações, em "escritório" das empresas de ensino para o credenciamento de instituições superiores de ensino.

Dados divulgados pela revista Veja, em maio de 2001, mostram a velocidade com que se expande o ensino superior no Brasil. Segundo o próprio texto, "um crescimento vertiginoso": 
Até 1997, a média de abertura de cursos superiores no país era de 200 ao ano. Em 1999 foram autorizados 745 novos cursos superiores e, em 2000, 865; • Entre 1996 e 2000 foram abertos 2016 novos cursos superiores em todo o Brasil, com permissão do Conselho Nacional de Educação (CNE); • Desse total, pelo menos $16 \%$ foram autorizados para o grupo Objetivo, tendo como relator Yugo Okida, sócio do empresário Di Genio, dono do grupo; - Dos 165 pedidos para autorização de abertura de novos cursos de psicologia no país, o conselheiro Yugo Okida aprovou apenas treze. Destes, cinco pertencem a faculdades de sócios do grupo Objetivo. O conselheiro Lauro Ribas Zimmer, ex-reitor da Universidade Estácio de Sá, do Rio de Janeiro, relata processos que autorizam a abertura de cursos da Estácio em outros Estados ou que permitem o aumento do número de vagas nas faculdades do grupo. (2 maio 2001)

A centralização das competências da CES-CNE no MEC, em relação às instituições não-universitárias, comprova a urgência do então governo em implementar suas políticas para a educação superior, dispensando publicamente os serviços do CNE. Essa atitude pode significar que as discussões travadas no interior do CNE estariam retardando o avanço das políticas do MEC para esse nível de ensino. Dessa forma, os empresários da educação superior e seus representantes estariam obtendo sucesso no interior do CES-CNE, ao impedir que as normas para avaliação dos cursos e das instituições de ensino superior, que incluem seu fechamento, valessem na prática. Isso significa dizer que a CES-CNE estaria facilitando demais a expansão do ensino privado, sem observar as regras definidas pelo próprio MEC.

É necessário registrar que, mesmo após essas mudanças nas atribuições do CNE, as denúncias de favorecimento de instituições privadas não acabaram. Em fevereiro de 2003, a imprensa divulgou a existência no MEC de um esquema irregular de autorização para cursos de ensino superior. A investigação detectou indícios de envolvimento de servidores da Secretaria de Educação Superior no favorecimento de instituições privadas de ensino. Em decorrência dessas irregularidades, foi realizada auditoria de todos os processos de autorização de novos cursos universitários aprovados no MEC, nos últimos quatro anos. Esse fato demonstra que as mudanças implementas no processo de autorização de cursos e instituições privadas não conseguiram alterar as práticas de clientelismo e corrupção no interior do CNE e do MEC. 


\section{REFLEXÕES FINAIS}

A partir da análise da legislação que regulamenta o CNE, criado em 1995, e de sua composição, é possível afirmar que sua história, "em ampla medida, é a história do progressivo desarmamento, por parte do Estado, desse órgão com instância de negociação de assuntos pendentes na área educacional" (Micelli, 2001, p. 308). Esse "desarmamento", iniciado através das primeiras regulamentações do CNE definidas por medidas provisórias (MPs) em 1995, buscou em um primeiro momento enfraquecer a autonomia do CNE em face do poder executivo mediante uma legislação que definiu seu caráter de assessoramento ao ministro.

Em um segundo momento, através da nomeação dos conselheiros, o governo FHC objetivou a redução, no interior do conselho, dos segmentos ligados à defesa do padrão universitário público e gratuito, contrários à privatização do ensino superior e à quebra do modelo universitário. Além disso, buscou o fortalecimento dos grupos representantes das instituições privadas mediante a nomeação de conselheiros vinculados a essas instituições.

Em um último momento, através de uma legislação que alterou as funções do CNE, ocorreu o esvaziamento político do próprio conselho como espaço de deliberações referentes ao ensino superior, principalmente o privado não-universitário.

$\mathrm{O}$ estudo demonstrou como o governo do presidente Fernando Henrique Cardoso procurou transformar o CNE em prolongamento do MEC. Entretanto, diante da organização e de pressões dos empresários do ensino superior, alterou seu projeto para o $\mathrm{CNE}$, ao retirar dele as deliberações sobre as instituições não-universitárias, foco importante de tensões. Se, inicialmente, o CNE constituiu-se em espaço de fortalecimento das políticas educacionais para a educação superior do governo, contraditoriamente, com a articulação da iniciativa privada e o aumento de seus representantes no interior do CNE, este lócus passou a resistir à implantação de mecanismos de controle e avaliação do ensino superior no país criado pelo governo. Esse fato pode ser observado, de um lado, pelos elevados números referentes à criação de instituições e de cursos superiores e, de outro, pelo não fechamento de nenhum curso avaliado negativamente pelo Provão, apesar do tão propalado rigor do MEC nesse processo de avaliação. 
As reflexões expostas contribuem para que o CNE seja repensado no sentido de sua democratização, transparência e construção enquanto aparelho do Estado. Ressaltam, ainda, a necessidade da redefinição do CNE como órgão normativo e de coordenação do sistema nacional de educação, bem como de sua composição e funções, como defendido na proposta de Plano Nacional de Educação da sociedade brasileira. Mais que isso, é preciso andar na contramão da história e defender um projeto soberano de país, no qual uma universidade pública e autônoma tenha papel indispensável.

\section{ABSTRACT}

This study analyzes the creation and performance of the Conselho Nacional de Educação(CNE) (National Educational Council) in the process of implementing policies for the expansion and diversification of third level institutes, by means of private enterprise, established during Fernando Henrique Cardoso's government. The CNE is understood as a locus where different projects for education in Brazil and specifically for third level education come face to face. To achieve this objective, this piece of research analyzes the main reforms in the organization and functions of the CNE and the background of its members as a means of getting to know the educational and third level teaching projects to which they are attached.

Keys words: Neoliberalism; privatization of third level education; Conselho Nacional de Educação

\section{NOTAS}

O presente texto faz parte e é resultado de um processo compartilhado de estudo e pesquisa do Coletivo de Estudos sobre Política Educacional. O Coletivo consiste em um grupo de estudos formado por professores e pósgraduandos do Programa de Pós-Graduação da Faculdade de Educação da Universidade Federal Fluminense.

1. Esses processos são marcados pelo emprego generalizado da ciência e da tecnologia nos processos produtivos e nos serviços e pela racionalização do trabalho que vem contribuindo para a intensificação da exploração da mais-valia relativa, para a precarização das relações de trabalho e para a ampliação do desemprego estrutural.

2. Os conselheiros são compreendidos neste trabalho não como portadores de vontades individuais, mas como representantes de vontades coletivas, ou 
seja, defensores de propostas para a educação nacional apresentadas pelas entidades da sociedade civil que participam da indicação de nomes para compor o CNE.

3. Expressão utilizada por Armando Boito Jr., no livro Política neoliberal e sindicalismo no Brasil (1999), para caracterizar a fração da nova burguesia de serviços que vem se fortalecendo no país em decorrência da política neoliberal de redução dos gastos públicos e dos direitos sociais. Dessa forma, a nova burguesia de serviços vem se desenvolvendo em decorrência das políticas públicas de privatização da saúde, da educação e da previdência.

4. Os outros conselhos criados foram: Conselho Superior de Ensino (Reforma Rivadávia Corrêa, 1911); Conselho Superior de Ensino (Reforma Carlos Maximiliano, 1915) e Conselho Superior de Ensino (Reforma Rocha Vaz, 1925).

5. Romanelli (1978), ao analisar a composição do CNE, aponta a existência de "duas falhas graves: primeira delas é a ausência total de representação do magistério ou do pessoal ligado ao ensino primário e o profissional; e a segunda é uma super-representação do ensino superior" (p. 140).

6. Miceli (2001) realizou interessante estudo sobre o Conselho Nacional de Educação, no período de 1931/1937. Ver Intelectuais à brasileira, São Paulo: Companhia da Letras, 2001.

7. Expressão utilizada por Miceli (2001), em estudo mencionado, referindo-se aos primeiros grupos de educadores especialistas que surgem no Brasil, nas décadas de 1920 e 1930. São exemplos desses profissionais Anísio Teixeira e Lourenço Filho.

8. Com essa reforma, o grupo que mais ampliou sua participação no CNE foi o da intelectualidade católica que, através dos católicos militantes, atuava na defesa do ensino privado e confessional. Com apenas um representante em 1931, passa para dois membros em 1935 e para quatro em 1936. Esse grupo reivindicava a legitimidade da Igreja para participar das reformas educacionais em curso e, assim, não ter ameaçado seu espaço de atuação no campo educacional.

9. A proposta original do Fórum, formulada pelo Cedes, conferia-lhe um caráter deliberativo.

10. A MP n. 938 de março de 1995, além de referir-se ao CNE, trata, pela primeira vez na legislação, de duas questões importantes para o ensino superior: a) da definição do processo de nomeação de reitores e vice-reitores de universidades e de diretores e vice-diretores de unidades universitárias isoladas federais, que deu origem à Lei n. 9.192/1995; e b) da criação dos "exames de avaliação dos conhecimentos adquiridos pelos alunos das últimas séries dos cursos de graduação das IES (art. 3º), que constituirá parte da Lei n. 9.131/1995. 
11. Carlos Alberto Serpa de Oliveira é ex-reitor da Universidade Gama Filho, do Rio de Janeiro; trabalhou no MEC em coordenações, comissões e assessorias (1969/76); presidente da Fundação Cesgranrio (desde 1971), entidade que aplica o Provão e dá consultoria a universidades privadas. Diretor da Academia Brasileira de Educação. (Dados extraídos da revista DocumentaCNE de mar. 1996).

12. Yugo Okida foi vice-reitor da UNIP, membro da ANUP, diretor administrativo do Colégio Objetivo, participou da comissão para a transformação das Faculdades Objetivo em UNIP. Foi membro do CFE de junho de 1988 a julho de 1994. (Dados extraídos da revista Documenta-CNE de mar. 1996).

13. Professor da Faculdade de Educação da UnB; vice-presidente da Anped no momento de sua indicação; indicado pela Anped.

14. Amiga pessoal de Paulo Renato e FHC. Professora titular da Faculdade de Filosofia, Letras e Ciências Humanas da USP. Foi secretária de política educacional do MEC até 1997. Foi indicada para o CNE para ocupar a vaga de Giannotti.

15. Professor do curso de Medicina da UERJ; reitor da UERJ; presidente da Abruem; vice-presidente do Crub; foi indicado pela Abruem.

16. Indicado pelo Crub; "Conselheiro do CNE. Irmão de Magno Maranhão, presidente da Anaceu, que reúne instituições de ensino superior privadas. A entidade dirigida por Magno Maranhão foi credenciada pelo MEC para indicar conselheiros para o CNE. Entre os três nomes apontados pela Anaceu está o de Éfrem." (Veja. São Paulo, n. 1701, 23 maio 2001. Educação).

17. Um forte exemplo da postura contrária ao ensino superior público consiste no artigo pago, publicado no JB, em 25/02/2000, no qual a UniverCidade Centro Universitário situado na cidade do Rio de Janeiro - apresenta tréplica ao artigo "A título de esclarecimento" do professor Giannotti, também publicado nesse jornal. O texto, entre outros tesouros, faz as seguintes críticas ao próprio Giannotti e às críticas que ele apresentou à proliferação do ensino superior no momento de sua saída do CNE: "O ilustre professor, ao defender o trancamento da expansão universitária, que segundo ele não tem controle do MEC, porque a verdade da farsa dos estatizantes está vindo à tona, num país que necessita de 8 milhões de novas vagas só para igualar-se ao nível educacional da Argentina, dá a impressão de estar desorientado e assustado com o progresso da vizinhança. A universidade sem pesquisa, a economia de mercado, o mundo globalizado, a internacionalização da informação e do conhecimento instantâneos, os investimentos de empresários bem-sucedidos em outros setores, na educação e na cultura, para o professor Giannotti, aparentam ser obras satânicas do capitalismo selvagem, quando tudo é produto do progresso da ciência. Durante sua geração, o Estado deixava nas 
ruas e à sanha da criminalidade mais de 15 milhões de crianças em idade escolar porque os recursos eram desviados para as universidades públicas. O Ministério da Educação aplicava mais de 65\% de seus recursos orçamentários no sustento das universidades gratuitas. Era a maior gastança nacional. (UniverCidade).

18. Foi indicado pela Associação Brasileira de Ciências. É reitor da Universidade Federal de Minas Gerais (Ufmg). Além de conselheiro da Capes, tem participação em diversas comissões de apoio a iniciativas do Ministério da Ciência e Tecnologia e do MEC. Por exemplo, na organização da recente Conferência Nacional de Ciência e Tecnologia. Atualmente, é Secretário da Educação Superior do MEC.

19. É conselheira desde março de 2000, indicada pela Social Democracia Sindical, braço do PSDB no movimento sindical. É professora e pesquisadora na área de sociologia na Universidade de Brasília (UnB).

20. Expressão utilizada por Lúcia Maria W. Neves (2002) para caracterizar o processo no qual o Estado delega ao empresariado do ensino e às instituições confessionais a formação técnica e ético-política do trabalho complexo. De acordo com Neves (2002), "o empresariamento do ensino no país vem-se processando majoritariamente nos cursos de graduação. Na pós-graduação, cabe ainda ao Estado a quase totalidade das matrículas, especialmente no que tange aos cursos de mestrado e doutorado" (p. 27).

21. A redação anterior do referido inciso era a de "cabe a CES/CNE deliberar sobre os relatórios encaminhados pelo Ministério da Educação e Desporto, sobre o reconhecimento de cursos e habilitações oferecidos por instituições de ensino superior [...]".

22. Texto do jornal Folha de S. Paulo, ao informar a suspensão dos processos da autorização de cursos superiores, anterior ao decreto, afirmava que "há suspeitas de facilitação de abertura de cursos superiores que envolvem integrantes do CNE". Paulo Renato afirmava que "Suspendemos para colocar ordem na casa". O artigo informava ainda que, naquele momento, havia 6.000 pedidos de novos cursos na fila e, desses, somente 700 referiam-se ao credenciamento de cursos em universidades (Folha S. Paulo, 6 jun. 2001).

23. Em entrevista, publicada na Folha de S. Paulo, em 23/07/2001, Eunice Durham critica a restrição de poderes do Conselho Nacional de Educação. Para ela, "tem havido um crescimento desmesurado do sistema privado de ensino superior, que está ameaçando a credibilidade do sistema no seu conjunto, principalmente porque desequilibra a proporção público e privado. $\mathrm{O}$ crescimento do ensino superior particular está sendo, em boa parte, governado pelo mercado, pelo processo de lucro, e isso é perigoso para o sistema." 
24. José Goldemberg, ex-ministro da Educação, em entrevista ao jornal da SBPC, afirmou que: "se a saída da prof ${ }^{a}$ Durham resolve um problema pessoal, não resolve o problema institucional. Enquanto ele não for resolvido a pressão dos empresários do ensino privado - e talvez até mesmo a corrupção continuarão. A MP 2.143-34 não vai resolver o problema, porque essas pressões se transferirão do CNE para um órgão burocrático ainda menos aparelhado que ele". (Jornal da Ciência. SBPC, 3 ago. 2001).

25. Naquele momento, Giannotti criticou o corporativismo do conselho que, para ele, possuía dois vícios de representação. O primeiro consistia no fato de que "certos dirigentes da política educacional e científica formam uma crosta armada por forte lealdade entre seus membros e fraca motivação para enfrentar as dificuldades de uma boa institucionalização do ensino e da pesquisa" (O Globo, 29 ago. 1997). O segundo refere-se aos representantes de instituições superiores que, mesmo sem condições de conciliar atividades de ensino, pesquisa e extensão, reivindicam a transformação dessas instituições em universidades. Isto se dá em decorrência das universidades terem garantida autonomia para, entre outros, criar cursos, gerando-se um "faz de conta" de ensino universitário. Ao criticar a transformação da Faculdade Anhembi-Morumbi em universidade, sem a institucionalização das condições necessárias para a realização da pesquisa, Giannotti afirma que a promessa de pesquisa, em algumas universidades, consiste em uma forma de merchandising. Nesse processo, Giannotti denuncia que o CNE recebeu pressões de toda espécie, inclusive da parte do ministro da Educação.

\section{REFERÊNCIAS}

BOITO JR., A. Política neoliberal e sindicalismo no Brasil. São Paulo: Xamã,1999.

FALEIROS, V. de P. Las funciones de la política social em el capitalismo. In: BORGIANI, E.; MONTANÕ, C. (Orgs.). La política social hoy. São Paulo: Cortez, 2000.

LAURELL, A. C. Avanzar al pasado: la política social del neoliberalismo. In: BORGIANI, E.; MONTANÕ, C. (Orgs.). La política social hoy. São Paulo: Cortez, 2000.

LOURENÇO FILHO, M. B. Organização e administração escolar. São Paulo: Edições Melhoramentos, 1967.

MICELI, S. Os intelectuais à brasileira. São Paulo: Companhia das Letras, 2001.

NEVES, L. W. LDB: projetos e processos. Rio de Janeiro, 1997 (mimeografado). 
. FERNANDES, R. R. Política neoliberal e educação superior. In.: NEVES, L. M. W. (Org.). O empresariamento da educação: novos contornos do ensino superior no Brasil dos anos de 1990. São Paulo: Xamã, 2002.

ROMANELLI, O. de O. História da educação no Brasil. Petrópolis: Vozes, 1978.

SAVIANI, D. A nova lei da educação: LDB - trajetória, limites e perspectivas. Campinas, SP: Autores Associados, 1997.

WEBER, S. Notas sobre o CNE e a qualidade do ensino superior. Educação $e$ Sociedade, Campinas, n. 80, set. 2002, p. 91-99.

\section{Jornais e revistas}

BERNARDES, Betina. Com atraso o MEC indica conselheiros. Folha de S. Paulo, São Paulo, 11 mar. 1998.

DIEGUEZ, Consuelo, Ação entre amigos. Conselho de Educação autoriza abertura de faculdades de parentes e sócios dos conselheiros. Veja, 2 maio 2001.

DOCUMENTA. Brasília, n. 418, Publicação Oficial do Conselho Nacional de Educação, mar. 1996.

FOLHA DE S. PAULO. Não há nova regra, diz MEC. São Paulo, 19 jan. 1998.

GIANNOTTI, José Arthur. Último conselho. O Globo, Rio de Janeiro, 29 ago. 1997.

GOIS, Antônio. Eunice Durham sai do CNE após decreto que tirou poder do conselho. Amiga do presidente deixa governo. Folha de S. Paulo, São Paulo, 19 jul. 2001

Antropóloga deixa vaga no Conselho Nacional de Educação criticando ações de Paulo Renato. Folha de S. Paulo, São Paulo, 23 jul. 2001.

JORNAL DA CIÊNCIA. "É difícil segurar o ensino privado que se tornou um grande negócio”. SBPC, Rio de Janeiro, 3 ago. 2001.

PARAGUASSÚ, Lisandra. Suspeita de irregularidades envolvendo Conselho Nacional de Educação forçou revisão de critérios. Folha S. Paulo, São Paulo, 6 jun. 2001.

SOUZA, Paulo Renato. Um exame é necessário. Folha de S. Paulo, São Paulo, 26 mar. 1995.

UNIVERCIDADE. Uma tréplica em defesa da UniverCidade. Jornal do Brasil, Rio de Janeiro, 25 fev. 2000.

YASSUDA, Selmy. Jornada múltipla. Conselheiros do MEC prestem assessoria a universidades que deveriam fiscalizar. Veja, 23 maio 2001. 